2014

\title{
Ticks and Spotted Fever Group Rickettsiae of Southeastern Virginia
}

\author{
Robyn M. Nadolny \\ Old Dominion University \\ Chelsea L. Wright \\ Old Dominion University \\ Daniel E. Sonenshine \\ Old Dominion University, dsonensh@odu.edu \\ Wayne L. Hynes \\ Old Dominion University,whynes@odu.edu \\ Holly D. Gaff \\ Old Dominion University, hgaff@odu.edu
}

Follow this and additional works at: https://digitalcommons.odu.edu/biology_fac_pubs

Part of the Microbiology Commons, and the Parasitology Commons

\section{Repository Citation}

Nadolny, Robyn M.; Wright, Chelsea L.; Sonenshine, Daniel E.; Hynes, Wayne L.; and Gaff, Holly D., "Ticks and Spotted Fever Group Rickettsiae of Southeastern Virginia" (2014). Biological Sciences Faculty Publications. 317.

https://digitalcommons.odu.edu/biology_fac_pubs/317

\section{Original Publication Citation}

Nadolny, R. M., Wright, C. L., Sonenshine, D. E., Hynes, W. L., \& Gaff, H. D. (2014). Ticks and spotted fever group Rickettsiae of southeastern Virginia. Ticks and Tick-Borne Diseases, 5(1), 53-57. doi:10.1016/j.ttbdis.2013.09.001 


\title{
Ticks and spotted fever group rickettsiae of southeastern Virginia
}

\author{
Robyn M. Nadolny\#, Chelsea L. Wright ${ }^{\#}$, Daniel E. Sonenshine, Wayne L. Hynes, and Holly \\ D. Gaff \\ Old Dominion University, Department of Biological Sciences, Norfolk, VA 23529, USA \\ \# These authors contributed equally to this work.
}

\begin{abstract}
The incidence of tick-borne rickettsial disease in the southeastern United States has been rising steadily through the past decade, and the range expansions of tick species and tick-borne infectious agents, new and old, has resulted in an unprecedented mix of vectors and pathogens. The results of an ongoing 4-year surveillance project describe the relative abundance of questing tick populations in southeastern Virginia. Since 2009, more than 66,000 questing ticks of 7 species have been collected from vegetation in a variety of habitats, with Amblyomma americanum constituting over $95 \%$ of ticks collected. Other species represented included Ixodes scapularis, Dermacentor variabilis, Amblyomma maculatum, Ixodes affinis, Haemaphysalis leporispalustris, and Ixodes brunneus. We found that 26.9-54.9\% of A. americanum ticks tested were positive for Rickettsia amblyommii, a non-pathogenic symbiont of this tick species. We also found no evidence of $R$. rickettsii in $D$. variabilis ticks, although they did show low infection rates of $R$. montanensis (1.5-2.0\%). Rickettsia parkeri and Candidatus R. andeanae were found in 41.8-55.7\% and 0$1.5 \%$ A. maculatum ticks, respectively. The rate of $R$. parkeri in A. maculatum ticks is among the highest in the literature and has increased in the 2 years since $R$. parkeri and A. maculatum were first reported in southeastern Virginia. We conclude that tick populations in southeastern Virginia have recently undergone dramatic changes in species and abundance and that these populations support a variety of rickettsial agents with the potential for increased risk to human health.
\end{abstract}

\section{Keywords}

Rickettsia parkeri; Rickettsia amblyommii; Rickettsia montanensis; Amblyomma maculatum; Amblyomma americanum; Dermacentor variabilis

\section{Introduction}

Ticks are ectoparasitic vectors of disease-causing microorganisms with complex life histories that are intimately tied to their hosts and the habitats in which they are found. Each species of human-biting tick is a vector for a different suite of infectious agents. There is great variation in the dominant tick species in different regions of the United States (Merten

\footnotetext{
(c) 2013 Elsevier GmbH. All rights reserved.

* Corresponding author. Old Dominion University, Department of Biological Sciences, Mills Godwin Building, Room 10, Norfolk, VA, USA 23529. Tel.: +1 (757) 683-6903; fax: +1 (757) 683-5283. hgaff@ odu.edu (Holly Gaff).

Publisher's Disclaimer: This is a PDF file of an unedited manuscript that has been accepted for publication. As a service to our customers we are providing this early version of the manuscript. The manuscript will undergo copyediting, typesetting, and review of the resulting proof before it is published in its final citable form. Please note that during the production process errors may be discovered which could affect the content, and all legal disclaimers that apply to the journal pertain.
} 
and Durden, 2000; Stromdahl and Hickling, 2012). Much of the recent work on the ecology of ticks and their associated pathogens has been done in the northeastern United States, where Lyme disease has become a major human health threat in recent decades (Ostfeld et al., 1995; LoGiudice et al., 2003). However, recent increases in rickettsial infections such as those caused by Rickettsia parkeri and related organisms such as Ehrlichia chaffeensis and Anaplasma phagocytophilum have drawn the focus of some research to the southeastern United States. The community of human-biting ticks in the southeast is dramatically different than that of the northeast. In the southeast, Amblyomma americanum, the lone star tick, is the primary human-biting tick, while in the northeast, the blacklegged tick, Ixodes scapularis, and the American dog tick, Dermacentor variabilis, are the predominant humanbiting ticks (Merten and Durden, 2000; Stromdahl and Hickling, 2012). Although differences in the dominant human-biting ticks have been noted, there is a dearth of longterm surveillance on the tick communities in the southeast, the pathogens that questing southeastern ticks carry, and how these numbers are changing over time.

The range expansion of tick populations from the southeast into the mid-Atlantic region has had a serious impact on human cases of tick-borne diseases. Perhaps the most dramatic change has been the increase in numbers of A. americanum and its associated pathogens during the past several decades (Childs and Paddock, 2003; Paddock and Yabsley, 2007). Increased white-tailed deer (Odocoileus virginianus) populations and expanded forested habitat have led to the increase in A. americanum ticks and an expansion of their range (Paddock and Yabsley, 2007). Since 2010, 2 new species of tick have established permanent populations in southeastern Virginia. The Gulf Coast tick, Amblyomma maculatum, has established several populations in southeastern Virginia and brought with it $R$. parkeri, the agent of Tidewater spotted fever (also known as "Rickettsia parkeri rickettsiosis") (Wright et al., 2011). In addition, Ixodes affinis, a known sylvatic vector for Borrelia burgdorferi, the causative agent of Lyme disease, has also established populations throughout southeastern Virginia (Nadolny et al., 2011). The addition of 2 new species to a tick community has unpredictable impacts on pathogen prevalence and tick species community structure.

The spotted fever group rickettsiae (SFGR) consists of multiple species ranging from nonpathogenic organisms such as Rickettsia amblyommii to potentially lethal pathogens such as Rickettsia rickettsii, the causative agent of Rocky Mountain spotted fever. Rickettsia amblyommii is found primarily in A. americanum, and reported prevalence is variable and ranges from 0\% to 84\% in the United States (Childs and Paddock, 2003; Mixson et al., 2006; Moncayo et al., 2010; Smith et al., 2010). Although it is has not been conclusively established that $R$. amblyommii is pathogenic to humans, there is some evidence suggesting that it is capable of causing human infection (Apperson et al., 2008; Billeter et al., 2007). Another SFGR, $R$. montanensis, is associated with $D$. variabilis. Although generally considered to be nonpathogenic, $R$. montanensis was recently associated with an afebrile rash illness (McQuiston et al., 2012). Reported prevalence of $R$. montanensis in D. variabilis is generally low, ranging from $3.2 \%$ in D. variabilis collected from humans (Stromdahl et al., 2011) and 3.8\% in D. variabilis from Maryland (Ammerman et al., 2004) to $10 \%$ in $D$. variabilis from Tennessee (Moncayo et al., 2010). Rickettsia parkeri is a pathogenic SFGR primarily transmitted by A. maculatum. Reported prevalence of $R$. parkeri in A. maculatum ranges from 1.4\% to 43.1\% (Paddock et al., 2010; Sumner et al., 2007; Cohen et al., 2009; Jiang et al., 2012; Trout et al., 2010; Wright et al., 2011; Fornadel et al., 2011; VarelaStokes et al., 2011; Jiang et al., 2012; Ferrari et al., 2012). Also found in A. maculatum is Candidatus Rickettsia andeanae, a SFGR of unknown pathogenicity. Reported prevalences of Candidatus R. andeanae in ticks vary from $0.6 \%$ to $10 \%$ (Fornadel et al., 2011; Jiang et al., 2012; Varela-Stokes et al., 2011; Wright et al., 2011; Ferrari et al., 2012; Sumner et al., 2007; Paddock et al., 2010). 
We have been conducting active tick surveillance throughout southeastern Virginia since 2009 , with intensive year-round surveillance since 2010. The purpose of our surveillance has been to describe the tick and tick-borne disease-causing pathogen populations in southeastern Virginia, determine which species are the most abundant, and document changes in species composition over time. Ticks collected from the region have been tested for several members of the SFGR. All of this information will be used to develop and parameterize predictive mathematical models assessing the risk of human disease in this region. Here, we describe the results of our surveillance and the rates of SFGR infection found in the ticks of southeastern Virginia.

\section{Materials and methods}

Questing ticks were collected from 13 sites in 8 counties and cities throughout southeastern Virginia, comprising a mix of habitats and degrees of human disturbance (Fig. 1). Sites were selected across the region to provide a variety of landscapes including 3 urban parks, 4 government installations, 4 state parks/preserves, a National Wildlife Refuge, and a Nature Conservancy site. The majority of the sites were chosen to parallel studies conducted in the region by Sonenshine and others from the 1960s through the 1980s (Sonenshine et al., 1966, 1995; Sonenshine, 1979). Additional sites were added to so that there was a sampling site in every county and city in the region. Each site is composed of one or more transects ranging from $100 \mathrm{~m}$ to $800 \mathrm{~m}$ long, with one $2000 \mathrm{~m}$ long transect through the Nature Conservancy site in a late secondary successional tract. Each individual transect is confined to one particular habitat for a total of approximately $1500 \mathrm{~m}$ of grass-dominated, $1800 \mathrm{~m}$ of edge, and $3000 \mathrm{~m}$ of wooded habitat. The number of transects at each site was determined by the variety of habitats present with the goal of having one grass-dominated habitat, one closed canopy wooded habitat, and one edge habitat. The same transects have been flagged each time the site was visited, resulting in a consistent area being sampled during each collection trip. Sampling was conducted at 10 sites comprising 24 transects in 2010, 13 sites comprising 33 transects in 2011, and 12 sites comprising 29 transects in 2012. Each site was sampled monthly during the winter months when tick density is low, but was sampled weekly or bi-weekly when tick densities are high from May through October (Table 1).

Questing ticks were collected using flags constructed from 1- $\mathrm{m}^{2}$ white denim squares attached to dowel rods and swept through low vegetation and along the ground as described previously (Ginsberg and Ewing, 1989). Flags were inspected for ticks every few meters, and careful training was provided to ensure consistency of collection. Adult and nymphal ticks were collected from the flag with forceps, while larvae were collected immediately with masking tape before being placed in vials and brought back to the lab for morphological identification. Flags were carefully checked between transects and washed between sites to ensure collection of all ticks and prevent contamination of the next sample. Each tick was morphologically identified to species (Keirans and Clifford, 1978; Keirans and Litwak, 1989; Oliver et al., 1987) and then frozen at $-20^{\circ} \mathrm{C}$ until processed for pathogen testing.

Amblyomma americanum and D. variabilis adults were pooled in groups of up to 10 for DNA extraction and pathogen testing; A. americanum nymphs were grouped in pools of up to 25 for testing. Pools were restricted to ticks collected from the same transect on the same day. All other ticks were individually extracted and tested. Every adult tick was cut in half, one half used for analysis, the other half stored at $-80^{\circ} \mathrm{C}$ for future analyses or validations. DNA was extracted using the DNeasy Blood and Tissue Kit (Qiagen Inc., Valencia, CA) according to the manufacturer's protocol and stored at $-20^{\circ} \mathrm{C}$ until analyzed. 
DNA samples were tested for rickettsial DNA by real-time PCR using a MiniOpticon RealTime PCR System (BioRad Laboratories, Hercules, CA). Samples were tested for Rickettsia spp., R. amblyommii, R. montanensis, $R$. parkeri, or Candidatus R. andeanae DNA using quantitative PCR (qPCR) (Table 2). Reactions were carried out using EconoTaq PLUS 2X Master Mix (Lucigen Corp., Middleton, WI), 0.5-0.7 $\mu \mathrm{M}$ of each primer, 0.4-0.5 $\mu \mathrm{M}$ probe, 5-8 $\mathrm{mM} \mathrm{MgCl}_{2}$, and 2-5 $\mu \mathrm{L}$ DNA template in a final reaction volume of $20 \mu \mathrm{L}$. The PCR protocol for all reactions consisted of $50^{\circ} \mathrm{C}$ for $2 \mathrm{~min}, 95^{\circ} \mathrm{C}$ for $2 \mathrm{~min}$, and then 45 cycles of $95^{\circ} \mathrm{C}$ for $15 \mathrm{~s}$ and $60^{\circ} \mathrm{C}$ for $30 \mathrm{~s}$. A select number of positive samples were periodically sampled and Rickettsia species confirmed by DNA sequencing.

Because A. americanum and D. variabilis tick DNA was extracted in pools, a maximum likelihood estimation (MLE) was used to approximate true infection rate of $R$. amblyommii and $R$. montanensis, respectively. The software used to perform MLE was developed by Brad Biggerstaff and acquired from the Centers for Disease Control and Prevention website (CDC, 2013a).

\section{Results}

From 2010 to 2012, 66,590 questing ticks were collected from southeastern Virginia. Amblyomma americanum comprised $96.5 \%$ of all ticks collected. The majority of the $A$. americanum were larvae collected during the late summer, comprising $76.5 \%$ of the $A$. americanum collected. Excluding larvae, A. americanum adults and nymphs still accounted for more than $87 \%$ of ticks collected (Table 3). Four other species of ticks were commonly collected using flags, including D. variabilis, I. scapularis, and A. maculatum, as well as I. affinis (Table 3). These trends were similar for grass, edge, and wooded sampling sites. The one site undergoing late secondary succession had higher percentages of $D$. variabilis and $A$. maculatum, but still had a majority A. americanum of more than $60 \%$.

There was an increase in the total number of ticks collected each year, which can be explained by the addition of transects in 2011 and an increase in transect sampling events each year (Table 1). Sites that were sampled monthly or bi-weekly in 2010 and 2011 were increased to weekly sampling in 2012. However, even with the increase in collections in 2012 , the average number of ticks collected per sampling trip remained roughly the same between 2011 and 2012. Rickettsia amblyommii was detected in over 72.5\% of $A$. americanum pools tested (Table 4). Maximum likelihood estimates placed $R$. amblyommii at an average prevalence (adults and nymphs) at $26.9 \%$ in 2010 and $54.9 \%$ in 2011. Rickettsia montanensis was found in 5.6-6.9\% of D. variabilis pools tested. Maximum likelihood estimates placed $R$. montanensis prevalence at $1.5 \%$ in 2010 and $2.0 \%$ in 2011. All $D$. variabilis pools were initially tested for Rickettsia spp. DNA with positive samples being tested for $R$. montanensis. All samples positive for Rickettsia spp. were positive for $R$. montanensis. No evidence of $R$. rickettsii, the causative agent of Rocky Mountain spotted fever, was found. Rickettsia parkeri prevalence in A. maculatum ranged from 43.1-55.7\%. In 2010, one A. maculatum adult was found to be positive for Candidatus Rickettsia andeanae (Table 4).

\section{Discussion}

We conclude that the tick community in southeastern Virginia is overwhelmingly dominated by $A$. americanum, with smaller but well-established populations of $D$. variabilis, $I$. scapularis, A. maculatum, and I. affinis. While populations of A. americanum, D. variabilis, and I. scapularis were expected in southeastern Virginia, populations of I. affinis and A. maculatum were unexpected when this surveillance project began. These 5 tick species are the ones a large host, e.g., white-tailed deer, are likely to encounter. Ixodes brunneus and 
Haemaphysalis leporispalustris were collected only incidentally by flagging, but it is likely that host-targeted collections of birds would yield substantial numbers of these ticks. The sheer numbers of A. americanum make it difficult to encounter anything other than this species during the times of year and in the habitats where they are abundant. This "lone star effect" swamps out the other species, especially during larval season and makes it impossible to assume that anything that might be true for tick population ecology in the northeast is applicable to tick communities in the southeast. The results of our survey may be representative of the tick community in other areas of the southeast, particularly along the coastal plain.

Rickettsia amblyommii and R. parkeri are the dominant SFGR found in Amblyomma spp. ticks in southeastern Virginia. Although it has not been established that $R$. amblyommii is pathogenic to humans, $R$. parkeri is a known pathogen, and its high prevalence in $A$. maculatum in southeastern Virginia (43-55\%) indicates that this tick may be an important disease vector in the region. Other reports of $R$. parkeri prevalence in southern states have generally been lower, ranging from 1.5\% (Trout et al., 2010) to 33\% (Varela-Stokes et al., 2011). Rickettsia parkeri prevalence in northern Virginia (Fornadel et al., 2011) was found to be comparable (41.4\%) to rates reported in this study, indicating that $R$. parkeri prevalence in Virginia is higher than in other states to the south and west.

Interestingly, no R. rickettsii was found in D. variabilis collected in 2010 and 2011. The absence of $R$. rickettsii and low prevalence of $R$. montanensis have also been observed in ticks collected from Tennessee in 2007 and 2008 (Moncayo et al., 2010) and from $D$. variabilis collected off of humans from 1997 to 2009 (Stromdahl et al., 2011). Despite the lack of $R$. rickettsii detected in this and other studies, reported cases of spotted fever group rickettsiosis continue to rise in Virginia. From 2002 to 2010 there was a 3-fold increase in the number of RMSF cases in Virginia (VDH, 2013); in 2011, RMSF cases were no longer reported as such by the CDC and were instead reported as a "spotted fever group rickettsiosis" (VDH, 2013). From 2010 to 2011, there was a 1.5-fold increase in the number of SFGR cases reported in Virginia with nearly a 3-fold increase in the eastern region of Virginia (VDH, 2013). Furthermore, the case fatality rate of Rocky Mountain spotted fever nationwide has decreased from $28 \%$ in 1944 to <1\% beginning in 2001 (CDC, 2013b). Our study reports no $R$. rickettsii in 522 questing D. variabilis tested from 2010 and 2011, which supports data from the Army Public Health Command's Human Tick Test Kit Program. They reported no ticks positive for $R$. rickettsii out of 106 ticks biting military personnel at Ft. Eustis, Virginia, from 1997 through 2012 (Stromdahl, pers. communication). Given the lack of $R$. rickettsii found in ticks in Virginia and other states, we suggest that this organism is no longer the primary cause of human infection diagnosed as spotted fever group rickettsiosis. Given the high prevalence of other SFGR, including $R$. parkeri, in southeastern Virginia, it is likely that these organisms have contributed to human cases reported as RMSF. It has also been suggested that Ehrlichia chaffeensis, a closely related species transmitted by A. americanum which causes acute symptoms similar to RMSF, may contribute to this misdiagnosis (Stromdahl et al., 2011).

In conclusion, A. americanum is by far the most commonly encountered human-biting tick in southeastern Virginia, harboring high levels of R. amblyommii. The composition of the tick community is undergoing changes as 2 invading species, A. maculatum and I. affinis, have established populations in this region. The SFGR populations have also undergone change with the absence of $R$. rickettsii and the influx of $R$. parkeri-infected A. maculatum, posing a new health threat to humans. It remains to be seen how the dynamic ecology of human-biting ticks and their associated SFGR will impact human health in the mid-Atlantic region in coming decades. Information about tick and SFGR ecology collected in this study will help parameterize models that will be used to predict the risk of tick-borne infections. 


\section{Acknowledgments}

We would like to thank Emily Pauler, Matt Benz, Joy Boyles, Ryan Wright, Brandon Rowan, Amanda Simmons, Lauren Jarkenski, Diana Lewis, Nicole Cox, Amy Johnson, Joseph Brown, John Warfle, David Cutherell, Caitlin Sciulli, Yong Suk Ko, Lindsey Bidders, Charles Abadam, Sara Blachman, Stefanie Snyder, Alexa McBride, and Eleanor Squires for their help in the field. We also acknowledge the Nature Conservancy, Weyanoke Bird and Butterfly Sanctuary, Back Bay National Wildlife Refuge, Kiptopeke State Park, York River State Park, First Landing State Park, Hoffler Creek Wildlife Refuge, and the Elizabeth River Project for permission to use their land. The project described was supported in part by grant no. K25AI067791 (to H.D.G.) from the National Institute of Allergy and Infectious Diseases. Ms. Wright was supported by the Henry M. Jackson Foundation, and Ms. Nadolny was supported by the Science, Mathematics and Research for Transformation (SMART) scholarship from the Department of Defense and the American Society for Engineering Education.

\section{References}

Ammerman NC, Swanson KI, Anderson JM, Schwartz TR, Seaberg EC, Glass GE, Norris DE. Spotted-fever group Rickettsia in Dermacentor variabilis, Maryland. Emerg Infect Dis. 2004; 10:1478-1481. [PubMed: 15496254]

Apperson CS, Engber B, Nicholson WL, Mead DG, Engel J, Yabsley MJ, Dail K, Johnson J, Watson DW. Tick-borne diseases in North Carolina: Is "Rickettsia amblyommii" a possible cause of rickettsiosis reported as Rocky Mountain spotted fever? Vector Borne Zoonot. Dis. 2008; 8:597606.

Billeter SA, Blanton HL, Little SE, Levy MG, Breitschwerdt EB. Detection of Rickettsia amblyommii in association with a tick bite rash. Vector Borne Zoonot. Dis. 2007; 7:607-610.

CDC. [June 13, 2013] Mosquito Surveillance Software. 2013a. <http://www.cdc.gov/westnile/ resourcepages/mosqSurvSoft.html>

CDC. [June 13, 2013] Statistics: Rocky Mountain spotted fever. 2013b. <http://www.cdc.gov/rmsf/ stats/>

Cohen SB, Yabsley MJ, Garrison LE, Freye JD, Dunlap BG, Dunn JR, Mead DG, Jones TF, Moncayo AC. Rickettsia parkeri in Amblyomma americanum ticks, Tennessee and Georgia, USA. Emerg Infect Dis. 2009; 15:1471-1473. [PubMed: 19788817]

Ferrari FA, Goddard J, Paddock CD, Varela-Stokes AS. Rickettsia parkeri and Candidatus Rickettsia andeanae in Gulf Coast ticks, Mississippi, USA. Emerg Infect Dis. 2012; 18:1705-1707. [PubMed: 23018026]

Fornadel CM, Zhang X, Smith JD, Paddock CD, Arias JR, Norris DE. High rates of Rickettsia parkeri infection in Gulf Coast ticks (Amblyomma maculatum) and identification of "Candidatus Rickettsia andeanae" from Fairfax County, Virginia. Vector Borne Zoonot. Dis. 2011; 11:1535-1539.

Ginsberg HS, Ewing CP. Comparison of flagging, walking, trapping, and collecting from hosts as sampling methods for northern deer ticks, Ixodes dammini, and lone-star ticks, Amblyomma americanum (Acari: Ixodidae). Exp Appl Acarol. 1989; 7:313-322. [PubMed: 2806016]

Jiang J, Stromdahl EY, Richards AL. Detection of Rickettsia parkeri and Candidatus Rickettsia andeanae in Amblyomma maculatum Gulf Coast ticks collected from humans in the United States. Vector Borne Zoonot. Dis. 2012; 12:175-182.

Keirans JE, Clifford CM. The genus Ixodes in the United States: a scanning electron microscope study and key to the adults. J Med Entomol. 1978; 15:1-38.

Keirans JE, Litwak TR. Pictorial key to the adults of hard ticks, family Ixodidae (Ixodida: Ixodoidea), east of the Mississippi River. J. Med. Entomol. 1989; 26:435-448. [PubMed: 2795615]

LoGiudice K, Ostfeld RS, Schmidt KA, Keesing F. The ecology of infectious disease: effects of host diversity and community composition on Lyme disease risk. Proc. Natl. Acad. Sci. U.S.A. 2003; 100:567-571. [PubMed: 12525705]

McQuiston JH, Zemtsova G, Perniciaro J, Hutson M, Singleton J, Nicholson WL, Levin ML. Afebrile spotted fever group Rickettsia infection after a bite from a Dermacentor variabilis tick infected with Rickettsia montanensis. Vector Borne Zoonot. Dis. 2012; 12:1059-1061.

Merten HA, Durden LA. A state-by-state survey of ticks recorded from humans in the United States. J Vector Ecol. 2000; 25:102-113. [PubMed: 10925803] 
Mixson TR, Campbell SR, Gill JS, Ginsberg HS, Reichard MV, Schulze TL, Dasch GA. Prevalence of Ehrlichia, Borrelia, and rickettsial agents in Amblyomma americanum (Acari: Ixodidae) collected from nine states. J Med Entomol. 2006; 43:1261-1268. [PubMed: 17162962]

Moncayo AC, Cohen SB, Fritzen CM, Huang E, Yabsley MJ, Freye JD, Dunlap BG, Huang J, Mead DG, Jones TF, Dunn JR. Absence of Rickettsia rickettsii and occurrence of other spotted fever group rickettsiae in ticks from Tennessee. Am J Trop Med Hyg. 2010; 83:653-657. [PubMed: 20810834]

Nadolny RM, Wright CL, Hynes WL, Sonenshine DE, Gaff HD. Ixodes affinis (Acari: Ixodidae) in southeastern Virginia and implications for the spread of Borrelia burgdorferi, the agent of Lyme disease. J Vector Ecol. 2011; 36:464-467. [PubMed: 22129422]

Oliver JH Jr. Keirans JE, Lavender DR, Hutcheson HJ. Ixodes affinis Neumann (Acari: Ixodidae): new host and distribution records, description of immatures, seasonal activities in Georgia, and laboratory rearing. J Parasitol. 1987; 73:646-652. [PubMed: 3598811]

Ostfeld RS, Cepeda OM, Hazler KR, Miller MC. Ecology of Lyme disease: habitat associations of ticks (Ixodes scapularis) in a rural landscape. Ecol Appl. 1995; 5:353-361.

Paddock CD, Yabsley MJ. Ecological havoc, the rise of white-tailed deer, and the emergence of Amblyomma americanum-assoctaed zoonoses in the United States. Curr Top Microbiol. 2007; 315:289-324.

Paddock CD, Fournier PE, Sumner JW, Goddard J, Elshenawy Y, Metcalfe MG, Loftis AD, VarelaStokes A. Isolation of Rickettsia parkeri and identification of a novel spotted fever group Rickettsia sp. from Gulf Coast ticks (Amblyomma maculatum) in the United States. Appl Environ Microbiol. 2010; 76:2689-2696. [PubMed: 20208020]

Sonenshine, DE. Ticks of Virginia (Acari, Metastigmata). Virginia Polytechnic Institute and State University; 1979.

Sonenshine DE, Atwood EL, Lamb JT. The ecology of ticks transmitting Rocky Mountain spotted fever in a study area in Virginia. Annals of the Entomological Society of America. 1966; 59:12341262. [PubMed: 5979107]

Sonenshine DE, Ratzlaff RE, Troyer J, Demmerle S, Demmerle ER, Austin WE, Jenkins S. Borrelia burgdorferi in eastern Virginia: Comparison between a coastal and inland locality. The American journal of tropical medicine and hygiene. 1995; 53:123-133. [PubMed: 7677212]

Smith MP, Ponnusamy L, Jiang J, Ayyash LA, Richards AL, Apperson CS. Bacterial pathogens in ixodid ticks from a Piedmont County in North Carolina: prevalence of rickettsial organisms. Vector Borne Zoonot. Dis. 2010; 10:939-952.

Stromdahl E, Hickling GJ. Beyond Lyme: etiology of tick-borne human diseases with emphasis on the southeastern United States. Zoonoses and Public Health. 2012; 59(Suppl. 2):48-64. [PubMed: 22958250]

Stromdahl EY, Jiang J, Vince M, Richards AL. Infrequency of Rickettsia rickettsii in Dermacentor variabilis removed from humans, with comments on the role of other human-biting ticks associated with spotted fever group Rickettsiae in the United States. Vector Borne Zoonot. Dis. 2011; 11:969-977.

Sumner JW, Durden LA, Goddard J, Stromdahl EY, Clark KL, Reeves WK, Paddock CD. Gulf Coast ticks (Amblyomma maculatum) and Rickettsia parkeri, United States. Emerg Infect Dis. 2007; 13:751-753. [PubMed: 17553257]

Trout R, Steelman CD, Szalanski AL, Williamson PC. Rickettsiae in Gulf Coast ticks, Arkansas, USA. Emerg Infect Dis. 2010; 16:830-832. [PubMed: 20409375]

Varela-Stokes AS, Paddock CD, Engber B, Toliver M. Rickettsia parkeri in Amblyomma maculatum ticks, North Carolina, USA, 2009-2010. Emerg Infect Dis. 2011; 17:2350-2353. [PubMed: 22172164]

VDH. [June 13, 2013] Tables of Selected Reportable Diseases in Virginia by Year of Report. 2013. <http://www.vdh.virginia.gov/Epidemiology/Surveillance/SurveillanceData/ReportableDisease/ index.htm>

Wright CL, Nadolny RM, Jiang J, Richards AL, Sonenshine DE, Gaff HD, Hynes WL. Rickettsia parkeri in Gulf Coast ticks, southeastern Virginia, USA. Emerg Infect Dis. 2011; 17:896-898. [PubMed: 21529406] 


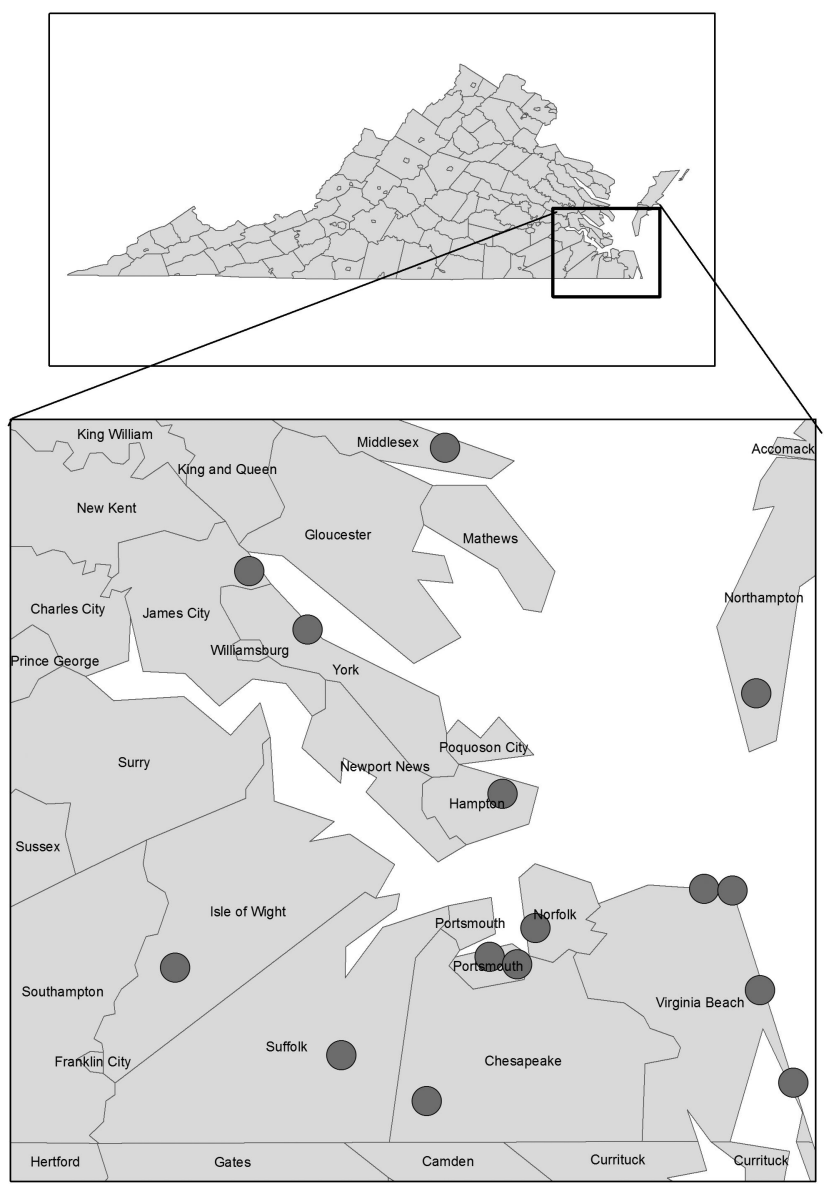

Fig. 1.

Map of collection sites throughout southeastern Virginia. 


\section{Table 1}

The number of sites sampled and total transect sampling events during 2010-2012. Also reported are the total number of ticks collected and the average number of ticks collected per sampling event each year.

\begin{tabular}{lccc}
\hline & $\mathbf{2 0 1 0}$ & $\mathbf{2 0 1 1}$ & $\mathbf{2 0 1 2}$ \\
\hline Sites sampled & 10 & 13 & 12 \\
Transect sampling events & 840 & 968 & 1921 \\
Total ticks collected & 13,263 & 17,055 & 34,216 \\
Average ticks including larvae/sampling event & 15.8 & 17.6 & 17.8 \\
\hline
\end{tabular}




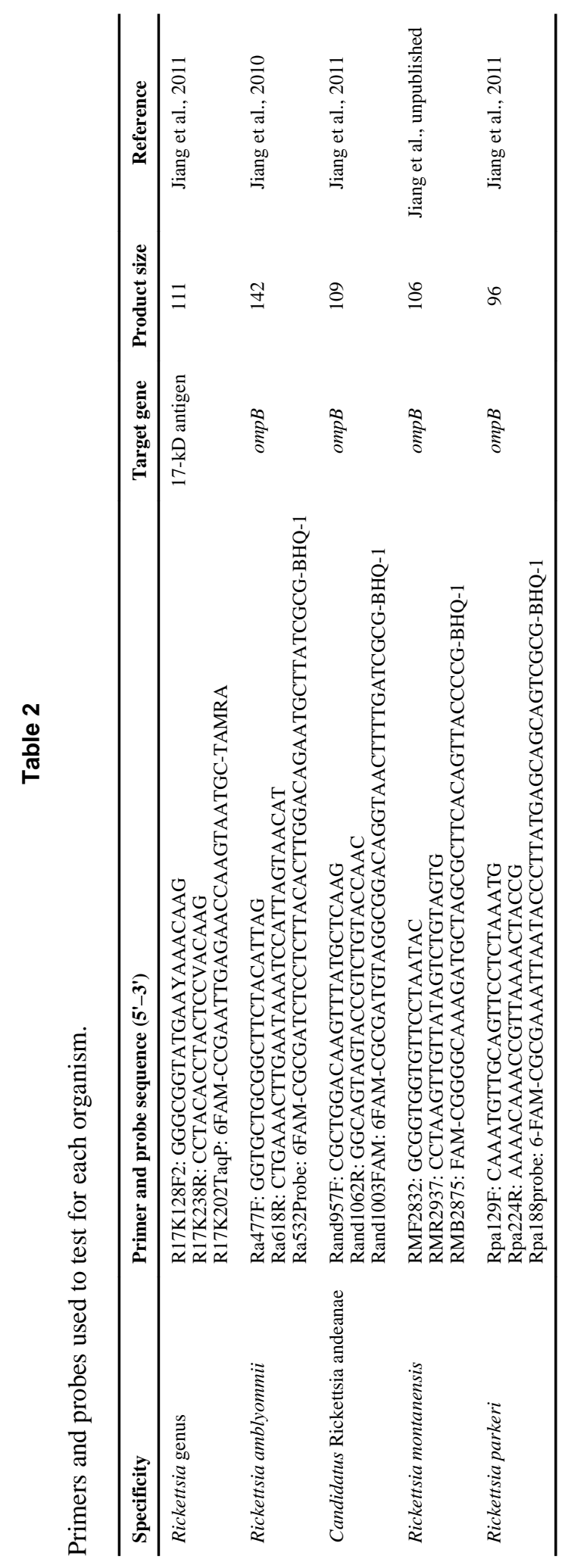

Ticks Tick Borne Dis. Author manuscript; available in PMC 2015 February 01. 
Table 3

Average number of questing ticks collected each year per sampling event (excluding A. americanum larvae). Total number collected given in parentheses.

\begin{tabular}{lccccc}
\hline Tick species & $\mathbf{2 0 1 0}$ & $\mathbf{2 0 1 1}$ & $\mathbf{2 0 1 2}$ & Total & Percentage of total \\
\hline I. brunneus & & & $0.002(3)$ & $0.001(3)$ & $0.02 \%$ \\
I. scapularis & $0.12(104)$ & $0.21(208)$ & $0.12(231)$ & $0.14(513)$ & $2.7 \%$ \\
D. variabilis & $0.33(280)$ & $0.34(326)$ & $0.22(416)$ & $0.27(1022)$ & $5.5 \%$ \\
A. maculatum & $0.09(74)$ & $0.12(116)$ & $0.08(145)$ & $0.09(335)$ & $1.8 \%$ \\
I. affinis & $0.10(81)$ & $0.16(152)$ & $0.09(177$ & $0.11(410)$ & $2.2 \%$ \\
A. americanum & $3.87(3250)$ & $5.63(5450)$ & $4.02(7731)$ & $4.41(16,431)$ & $87.8 \%$ \\
H. leporispalustris & $0.002(2)$ & $0.004(4)$ & $0.003(5)$ & $0.003(11)$ & $0.06 \%$ \\
Total & $4.51(3789)$ & $6.44(6238)$ & $4.53(8698)$ & $5.02(18,725)$ & $100.0 \%$ \\
\hline
\end{tabular}






